\title{
Industrial Melanism in the Peppered Moth, Biston betularia: An Excellent Teaching Example of Darwinian Evolution in Action
}

\author{
Michael E. N. Majerus
}

Published online: 6 December 2008

(C) Springer Science + Business Media, LLC 2008

\begin{abstract}
The case of industrial melanism in the peppered moth has been used as a teaching example of Darwinian natural selection in action for half a century. However, over the last decade, this case has come under attack from those who oppose Darwinian evolution. Here, the main elements of the case are outlined and the reasons that the peppered moth case became the most cited example of Darwinian evolution in action are described. Four categories of criticism of the case are then evaluated. Criticisms of experimental work in the 1950 s that centered on lack of knowledge of the behavior and ecology of the moth, poor experimental procedure, or artificiality in experiments have been addressed in subsequent work. Some criticisms of the work are shown to be the result of lack of understanding of evolutionary genetics and ecological entomology on the part of the critics. Accusations of data fudging and scientific fraud in the case are found to be vacuous. The conclusion from this analysis of criticisms of the case is that industrial melanism in the peppered moth is still one of the clearest and most easily understood examples of Darwinian evolution in action and that it should be taught as such in biology classes.
\end{abstract}

M. E. N. Majerus $(\bowtie)$

Department of Genetics, University of Cambridge,

Downing Street,

Cambridge CB2 3EH, UK

e-mail: m.majerus@gen.cam.ac.uk
Keywords Industrial melanism - Bird predation .

Evolution in action - Natural selection .

Genetic polymorphism $\cdot$ Peppered moth $\cdot$ Biston betularia

\section{Introduction}

Most people have heard of the peppered moth story. This is, in brief, the story of a moth, Biston betularia, that turned black following the industrial revolution and subsequently is turning back to its original white and black speckled pattern. But there is much more to the story than that, and over the last decade, the peppered moth story has been vigorously attacked by antievolutionists and strongly defended by those who accept Darwin's mechanism of natural selection as the driving force behind the adaptive characteristics of all organisms. At times, the exchanges have been acrimonious and have involved accusations of professional bullying, scientific fraud, data tampering, misquotation, misinterpretation born out of scientific ignorance, selective citation, and just plain lying. Some of the controversy has comprised highly personal attacks on scientists. Such attacks are of concern to the scientists and their families but need not detain us here. However, the debate has undermined the peppered moth as an illustrative example of Darwinian natural selection in action, and the tarnishing of this case has been used to attack Darwin's theory of evolution as a whole.

In this paper, I shall consider three questions. First, why did the peppered moth become the most quoted example of Darwinian evolution in action? Second, were the criticisms of the peppered moth story justified? Third, should the peppered moth story be taught in the classrooms and lecture 
rooms as an example that illustrates the central mechanism of Darwin's theory of evolution: natural selection?

\section{Why Did the Peppered Moth Become the Most Quoted Example of Darwinian Evolution in Action?}

The Peppered Moth Story: 1848-1960

Prior to 1848 , peppered moths in Britain where white or off-white, more or less speckled with black: the typica form (Fig. 1). In 1848, in Manchester, a black, or melanic, form of peppered moth, f. carbonaria (Fig. 2), was recorded (Edleston 1864). By 1895, 98\% of the Mancunian peppered moths were of this black form. A Victorian lepidopterist, J. W. Tutt, put forward an explanation of the rapid rise of this form in the 1890s (e.g., Tutt 1896). He recognized that following the industrial revolution, the environment in and around many urban parts of Britain had become despoiled by two major pollutants, sulfur dioxide, which kills lichens growing on tree bark and elsewhere, and air-borne particulate soot, which blackens the surfaces it lands upon. Consequently, Tutt conjectured that on the changed bark surfaces, the melanic moth was better camouflaged than the pale form and so fell victim to predation by birds less.

Tutt's hypothesis was initially rejected because both ornithologists and entomologists doubted that birds were major predators of night flying moths that depended on

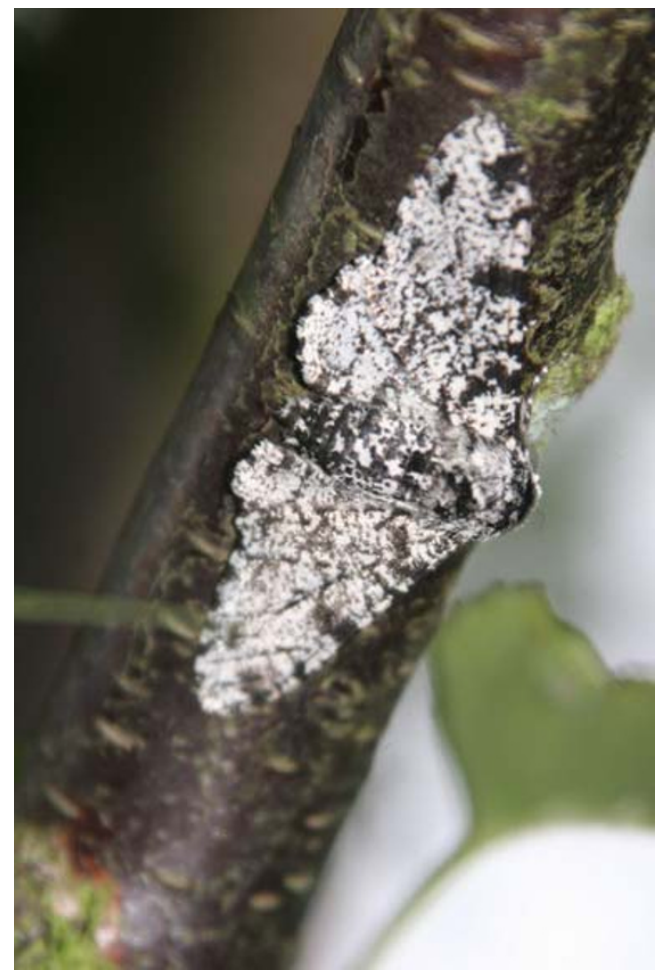

Fig. 1 The typica form of the peppered moth

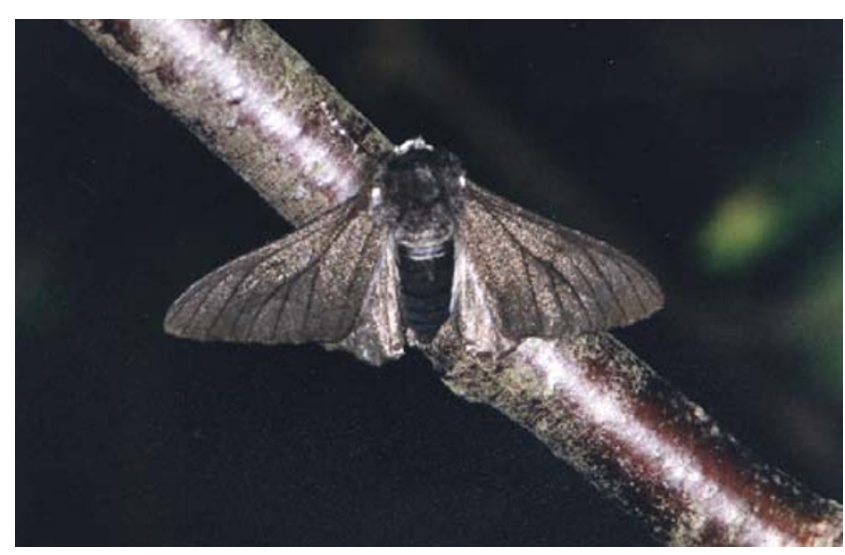

Fig. 2 The melanic carbonaria form of the peppered moth

crypsis for their defense during the day when they were inactive. The hypothesis was not tested experimentally for over half a century. In the 1950s, Kettlewell, working in Oxford under the guidance of E. B. Ford, conducted a series of experiments in two differing woodlands. One of these woodlands was in the Christopher Cadbury Bird Reserve in Birmingham, a heavily polluted mixed deciduous woodland, with the trees supporting virtually no lichens. The second was Deanend Wood in Dorset, a relatively unpolluted relict deciduous woodland supporting a diverse lichen flora. Kettlewell undertook experiments in Birmingham in 1953, and again in 1955, conducting similar parallel experiments in Dorset in the latter year. The two main experiments were predation experiments, including direct observation of predation, and mark-release-recapture experiments.

In his first Birmingham predation experiments, Kettlewell released live moths of each form onto tree trunks in the early morning and checked late in the day which moths were still present at their release points. Peppered moths do not fly in daylight, so disappearances were, reasonably, assumed to have been the result of predation. A significantly greater proportion of the carbonaria form $(62.57 \% ; n=366)$ were recovered compared to the typica form $(45.79 \% ; n=107)$ (Kettlewell 1955). Consequently, Kettlewell argued that carbonaria was at a selective advantage over typica in this polluted wood. In the mark-release experiment in Birmingham in 1953, 137 marked typica and 447 marked carbonaria were released. Samples collected subsequently, with pheromone assembly moth traps and mercury-vapor light moth traps, were checked for marks. The recapture rate for carbonaria $(27.5 \%)$ was double that of typica (13.1\%), supporting the view that the carbonaria form had greater fitness than typica in this polluted woodland (Kettlewell 1955).

When published, these results were received with the same skepticism that Tutt's hypothesis had received over half a century earlier. In addition, some evolutionary biologists were suspicious of the magnitude of the differences in fitness of the two forms suggested by Kettlewell's 
results (Kettlewell 1973). In consequence, Kettlewell determined to repeat the experiments, extending them to an unpolluted woodland, and to attempt to film parts of the experiments, including birds taking peppered moths from tree trunks. He persuaded the Dutch Nobel prize-winning ethologist, Professor Niko Tinbergen, to aid him with the filming. The experimental procedures used in the experiments in both woodlands in 1955 were similar to those used in 1953, except that a proper bird hide was used from which to film some of the released moths. Thus, for example, in one part of the predation experiment in Birmingham, three moths of each form were released onto a trunk in clear view of the hide. Once all three of one form had been taken, a new set of six was released. This was done and filmed during two mornings and an afternoon in a 3-day period, with 58 moths being eaten by a pair of redstarts, about three quarters (43) of those eaten being typica. Conversely, in Dorset, of 190 moths seen being eaten by birds, 86\% (164) were carbonaria (Kettlewell 1956). In the reciprocal markrelease-recapture experiments in 1955, recapture rates were $12.5 \%$ for typica and $6.3 \%$ for carbonaria in Dorset, against $25.0 \%$ for typica and $52.3 \%$ for carbonaria in Birmingham (Kettlewell 1956).

The reciprocal nature of Kettlewell's results in polluted and unpolluted woodlands provided convincing evidence in support of Tutt's differential bird predation hypothesis. This evidence was endorsed by survey work on the frequencies of the forms of the peppered moth throughout Britain. The first survey data showed a strong correlation between carbonaria frequency and industrial regions (Kettlewell 1958a). Later surveys showed more direct correlations between carbonaria frequencies and both sulfur dioxide and to a lesser extent soot pollutants (Kettlewell 1973; Lees and Creed 1975; Steward 1977; Bishop et al. 1978a) and a negative correlation between carbonaria frequency and lichen (Bishop 1972). These surveys alone provided convincing evidence that the peppered moth had evolved under the influence of natural selection, for no other known process could have led to such direct correlations between form frequencies and environmental factors.

The impact of Kettlewell's work on the peppered moth should not be underestimated. Its main import was to move the mechanism of Darwinian evolution from hypothesis to fact. As MacArthur and Connell (1966) wrote: "It used to be argued that natural selection was only a conjecture, because it had not been actually witnessed". But Kettlewell, along with Tinbergen, did witness it, and furthermore, they filmed it, so that others could see natural selection in action.

The prominence of the peppered moth as an example of "evolution in action" is a result of a combination of the features of the case. The phenotypic changes involved have visual impact and are due to a single gene mutation that obeys Mendelian laws of inheritance. The main environ- mental factor (industrial pollution) that had led to selective differences between the old form and new form were easy to comprehend. Moreover, it was obvious that the influence of this selective factor varied spatially. The changes had occurred in the recent past and indeed are still occurring. The agent of selection, differential bird predation, and the reason why the forms of peppered moth would be subject to different levels of selection in different places - the precision of the moths' camouflage-were easy for students to understand. There are many other examples of Darwinian evolution in action, but no other has this combination of rapid recent change, visual impact, and ease of understanding of the agent of selection.

The Peppered Moth Story: 1960-1998: The Post-Kettlewell Period

Kettlewell's verification of Tutt's hypothesis led to an upturn in research into industrial melanism in moths, much of which focused on the peppered moth. Over the next 40 years, a number of significant contributions were made. It should be noted that Kettlewell himself continued to work on melanism in the peppered moth and many other species (see Kettlewell 1973) until his death in 1979 and was throughout this period considered the leading authority on melanism in the Lepidoptera.

In the 1960s, the genetic control of an additional series of forms of the peppered moth, collectively known as the insularia complex, and all intermediate between typica and carbonaria, was determined (Clarke and Sheppard 1964; Lees 1968). These forms are controlled by additional alleles of the gene that controls carbonaria, and genetic dominance increases with increasing melanization. Several workers have sought information on the natural resting behavior of peppered moths through cage experiments and have cast doubt on whether peppered moths usually spend the day on tree trunks (Mikkola 1979, 1984; Liebert and Brakefield 1987).

There were also many additional independent field tests of the relative survival of typica compared with carbonaria during this period, all of which produced results that concurred with Tutt's hypothesis (Cook 2000, 2003; Mallett 2004). One of these entailed a series of experiments at sites along a transect running from the industrial northwest of England into rural north Wales. Here, assessment of the levels of predation of the two forms, at seven sites along the transect, showed that the melanic form was less prone to predation in the industrial region and became progressively more heavily predated to the southwest as the habitat became more rural and less polluted (Bishop 1972). This study included the first computer simulations of the course of melanic evolution, with the results of the simulation being qualitatively in agreement with observation. 
During this period, the first effects of the Clean Air Acts enacted in the 1950s and subsequent antipollution legislation, began to have an impact on the peppered moth. Many studies have reported declines in carbonaria frequencies from the late 1960s (Lees and Creed 1975; Cook et al. 1970; Whittle et al. 1976; Bishop et al. 1978b; Howlett and Majerus 1987; Mani and Majerus 1993). The most complete data set was collected on the Wirral, south of Liverpool (Clarke et al. 1985; Grant et al. 1996). Here, the frequency of carbonaria declined from about $90 \%$ in 1970 to less than $20 \%$ in 1995 . Critically, similar independent declines have been reported in other countries where antipollution legislation has been introduced, such as The Netherlands (Brakefield 1990; Brakefield and Liebert 2000) and the USA (Grant et al. 1995, 1996).

In the USA, the peppered moth is represented by the subspecies cognataria and has a melanic form, swettaria, which is phenotypically indistinguishable from carbonaria. Grant et al. $(1995,1996)$ stress the similarity in the pattern of decline in the frequency of the respective forms on the Wirral in England and at the George Reserve, 30 miles west of Detroit. In both places, the decline seen was from over $90 \%$ in 1959 to less than $20 \%$ in 1995 . The similarities between the declines in melanic frequencies in different countries are important. In science, when running laboratory experiments, the more often the same results are obtained in independent replicate experiments, the more confident one becomes of the results. Here then, the declines in Britain, the USA, and The Netherlands are, in effect, replicate natural experiments.

Perhaps the high point of the peppered moth's reputation as an example of Darwinian evolution in action was in November 1996, when the work of Grant et al. (1995, 1996) was reported in the New York Times (Yoon 1996). The changes in the peppered moth were explicable by Tutt's hypothesis, which had been tested and verified in a series of predation experiments. Predictions of what should happen to the peppered moth as the result of antipollution legislation had been made and these predictions were being fulfilled. Moreover, similar patterns had been seen in three different countries (Majerus 1998). Most importantly, the case had prominence because the change in the phenotype of the moth was so obvious. While natural selection has been demonstrated in studies on numerous other organisms, no other has the visual simplicity and impact of the peppered moth. However, just 2 years after this zenith, the case of industrial melanism in the peppered moth came under attack.

The Peppered Moth Story Under Attack: 1998-2003

In November 1998, a review of a book on melanism was published in Nature (Coyne 1998). The review, by
Professor Jerry Coyne, was of Melanism: Evolution in Action (Majerus 1998). Coyne's review asserts that the book shows the case of the peppered moth, "to be in bad shape." He says that his own reaction to reading the two chapters specifically on the peppered moth resembled, "the dismay attending my discovery, at the age of six, that it was my father and not Santa who brought the presents on Christmas Eve." Coyne's main conclusion was, "for the time being we must discard Biston as a well-understood example of natural selection in action."

Donald Frack, an American scientist who has many times locked horns with advocates of Special Creation and Intelligent Design, dismisses Coyne's review, writing; "There is essentially no resemblance between Majerus' book and Coyne's review of it. If you pick through the book, you might be able to argue for Coyne's accuracybut only at the expense of completely ignoring the majority of the text and all of Majerus' intent. If I hadn't known differently, I would have thought the review was of some other book" (Frack 1999). However, Coyne's review was followed by a series of articles in the popular press, in book chapters, and published on web-sites, but notably not in peer-reviewed scientific journals, with titles such as: Scientists pick holes in Darwin moth theory (Matthews 1999), Second thoughts about peppered moths (Wells 2001), Darwinism in a flutter (Smith 2002), The moth that failed (Raeburn 2002), Staple of evolutionary teaching may not be a textbook case (Wade 2002), Moth-eaten statistics (Wells 2002), and The Piltdown Moth (Rudd 2001). These articles speak of a conspiracy of silence over problems with the peppered moth story, of a series of scientific blunders, and of experiments designed to come up with the "right" answer. Then, in 2002, writer and journalist Judith Hooper published a book, Of Moths and Men: Intrique, Tragedy and the Peppered Moth (Hooper 2002). Here, for the first time, were thinly veiled accusations of data fudging and fraud aimed at Kettlewell.

\section{Were the Attacks on the Peppered Moth Story Justified?}

Before reviewing the criticisms aimed at the peppered moth case and their validity, two points should be made. First, almost all of the criticisms of the case as an example of evolution in action are aimed at Kettlewell's work and the role of his mentor Professor E. B. Ford. There is little reference to the independent work on the peppered moth over the last four decades of the twentieth century (Cook 2003; Majerus 1998; Lees 1981; Brakefield 1987 for reviews). Such work is only mentioned when carefully selected passages, often taken out of context, are used to support criticisms of the case. Second, there is no mention 
of the many other species of moth (over 100 species in Britain alone) that exhibit industrial melanism (Kettlewell 1973; Majerus 1998 for reviews; Fig. 3).

The criticisms of the peppered moth case can be broadly split into four categories:

1. Issues of ignorance of the ecology and behavior of the moth

2. Issues of artificiality or poor procedure in experimental protocols

3. Pseudoscientific criticisms

4. Data manipulation and/or scientific fraud

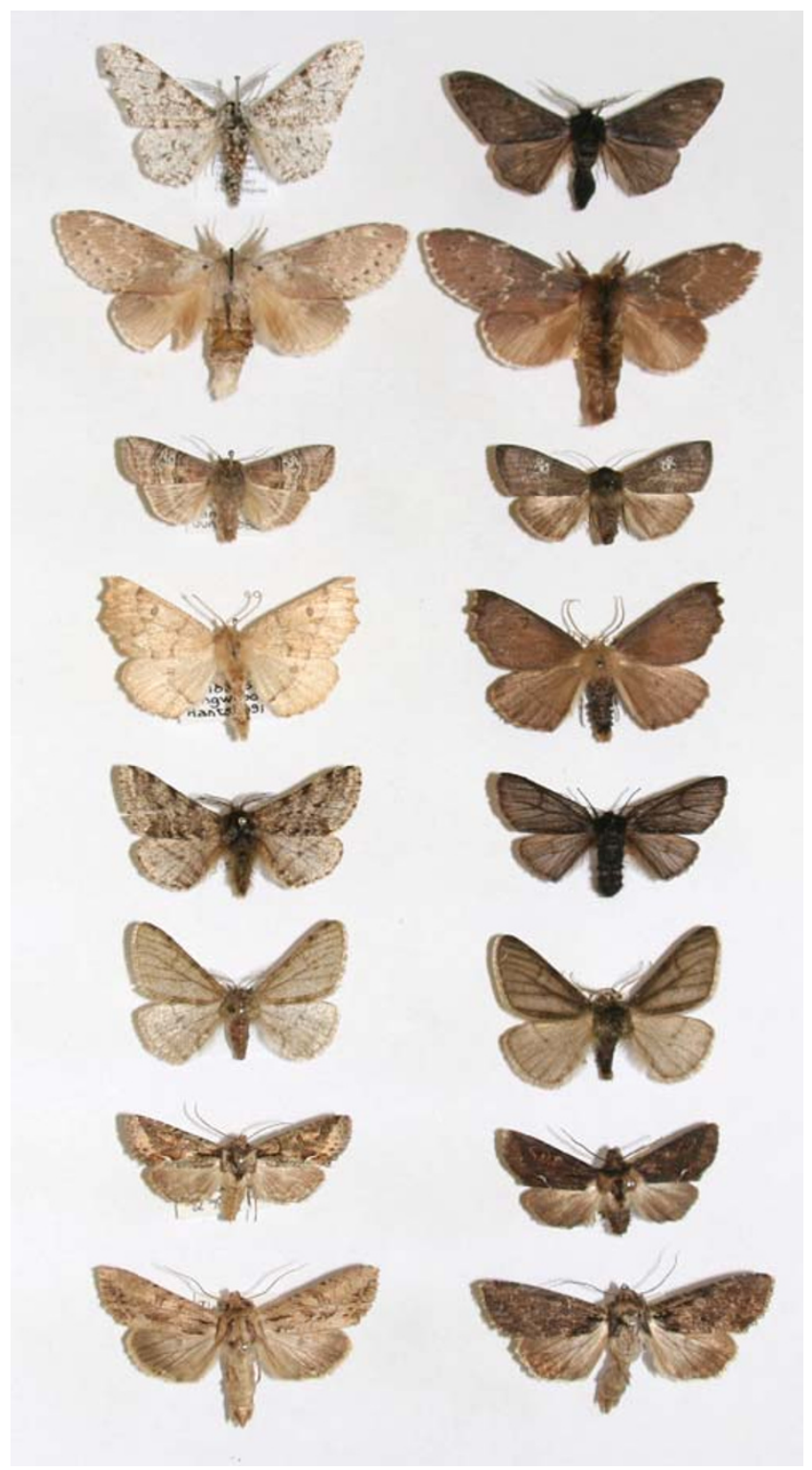

Fig. 3 Nonmelanic (left) and industrial melanic (right) forms of some British moths. From top to bottom: peppered moth-Biston betularia, lobster moth-Stauropus fagi, figure of eighty-Tethea octogesima, scalloped hazel — Gonodontis bidentata, brindled beauty — Lycia hirtaria, pale brindled beauty-Apocheima pilosaria, green brindled crescentAllophyes oxyacanthae, dark arches-Apamea monoglypha
Issues of Ignorance of the Ecology and Behavior of the Moth

Most of the criticisms in this category have come from scientists working with the peppered moth, including Kettlewell himself. Perhaps preeminent among the problems in this category have been difficulties in understanding the dispersal dynamics of the moth, lack of knowledge of the longevity of the moth, and a paucity of observations of peppered moths at rest in the wild during the day.

The main elements of the dispersal characteristics of the peppered moth are now accepted to comprise the flight of adult male moths, the more limited flight of adult female moths, and wind-assisted movement of newly hatched larvae on silken threads (Liebert and Brakefield 1987; Brakefield and Liebert 1990). These dispersal patterns and particularly the movement of first instar larvae are important in explaining the frequency drift of the melanic allele into rural regions to the northeast of industrial centers: Larvae are blown by southwesterly prevailing winds in the "aerial plankton." Adult longevity in the peppered moth and the temporal dynamics of reproduction through adult life in this species were assessed by Bishop (1972).

The paucity of observations of peppered moths in their natural resting sites has often been highlighted (e.g., Clarke et al. 1985; Wells 2001; Hooper 2002). For example, Clarke et al. wrote, "all we have observed is where the moths do not spend the day. In 25 years we have only found two betularia on the tree trunks or walls adjacent to our traps and none elsewhere" (Clarke et al. 1985). This is important, because many have assumed that, as Kettlewell released moths onto tree trunks, this is where peppered moths spend the day. In fact, Kettlewell (1958b) suspected that peppered moths did not usually rest by day in exposed positions on tree trunks, for he wrote, "whilst undertaking large-scale releases of both forms in the wild at early dawn, I have on many occasions been able to watch this species taking up its normal resting position which is underneath the larger boughs of trees, less commonly on trunks." It seems likely, therefore, that the reason that Kettlewell released his moths onto tree trunks was simply experimental expediency: on tree trunks, it would be easier to see what was going on.

There is now considerable circumstantial evidence from cage experiments that peppered moths do not usually rest in exposed positions on tree trunks but prefer horizontal branches (Mikkola 1979, 1984; Liebert and Brakefield 1987). Field observations of peppered moths found serendipitously lead to the same general conclusion (Howlett and Majerus 1987; Majerus 1998). The largest data set of peppered moths found in the wild was accumulated during a predation experiment that involved researchers climbing trees at dusk and dawn during the flight season of the moth 
(May to August) over 6 years. Of 135 peppered moths found, $50 \%$ were on horizontal branches (Fig. 4), 37\% on trunks (Fig. 5), and 13\% were on smaller twigs or in foliage (Majerus 2007). Therefore, although Kettlewell's predation experiments have been criticized as being artificial because he released them onto tree trunks, it appears that this element of his protocol was not as flawed as some (e.g., Majerus 1998; Wells 2001) have previously thought.

One question that must be addressed in the light of this finding is, why did Clarke and his colleagues found so few peppered moths at rest during all their years of research? My opinion is that they, like most humans, are simply not very good at seeing peppered moths in their naturally chosen resting positions. There is some circumstantial experimental evidence to support this view. An experiment was conducted to test the efficiency of the technique used in some predation experiments that entailed gluing dead moths onto trees in "life-like" positions (e.g., Bishop 1972; Howlett and Majerus 1987). Peppered moths of each of the different forms, set with their wings in natural resting postures, were glued onto birch trunks with a view to maximizing their camouflage. An equal number of live moths were then released onto the same trunks at dawn and allowed to walk up the trunks until they clamped down. Students were then asked to walk toward the birch trunks from $10 \mathrm{~m}$ away, having been told that there were six moths to find. When one meter from the trunk, the subjects had to stop and could continue to search for the moths for one further minute. The experiment produced two major conclusions. First, the live moths were significantly harder to see than the dead glued moths. Second, none of the students found all the moths despite knowing that the moths were present in a very restricted area, indicating that people with little experience of looking for cryptic moths are not very good at spotting them (Majerus et al., unpublished data).

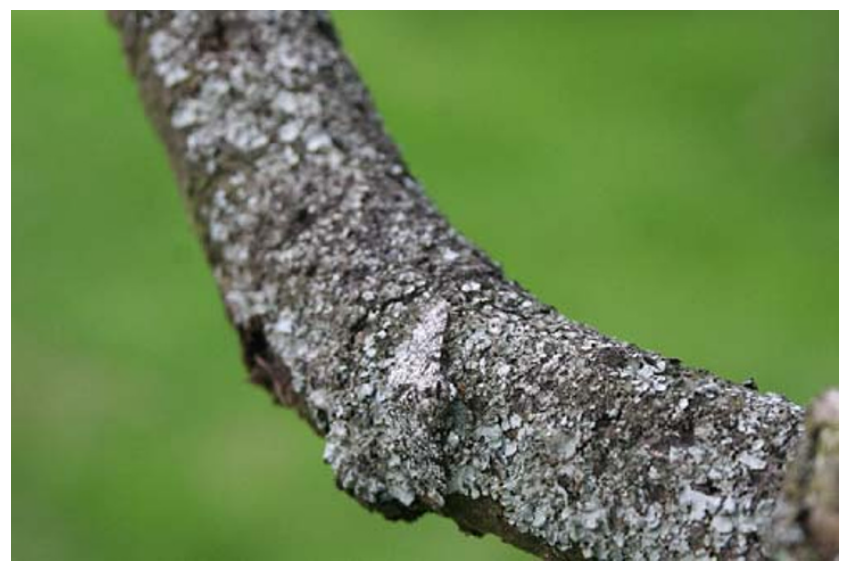

Fig. 4 A peppered moth found at rest on a horizontal tree branch

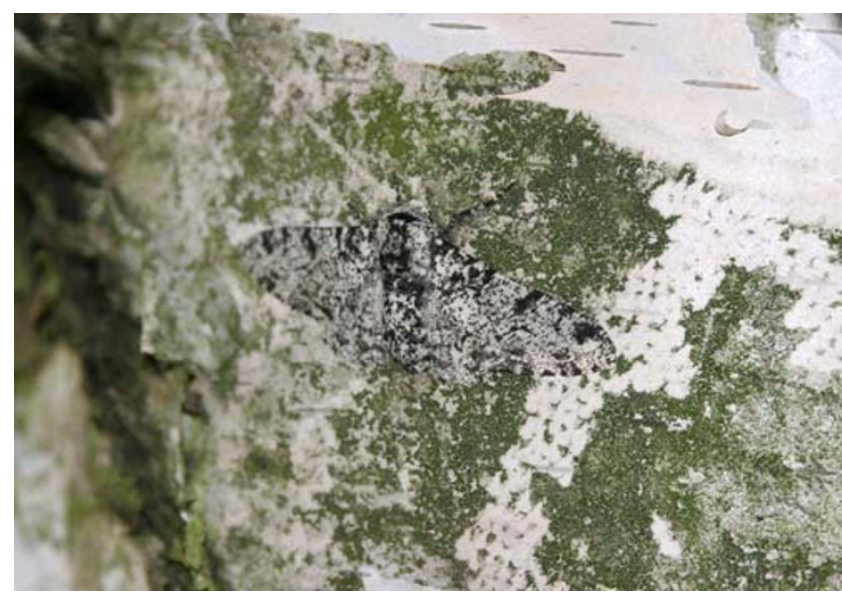

Fig. 5 A peppered moth found at rest on a vertical tree trunk

Issues of Artificiality or Poor Procedure in Experimental Protocols

There have been many criticisms of Kettlewell's experiments beyond that concerned with his releasing moths onto tree trunks:

1. In his predation experiments, he often repeatedly used the same trees to release the moths onto, potentially producing a "bird table effect".

2. In his mark-release-recapture experiment, he released moths at high frequencies, which may have produced an area of local high prey abundance, and birds may have developed a searching image for peppered moths, leading to abnormally high levels of predation.

3. In both types of experiment, he released moths during daylight hours. Peppered moths are very reluctant to fly in daylight. Those prompted to fly in the day will clasp the first substrate that they contact and within a few centimeters settle fully, "clamping down" against the substrate and then staying still. In consequence, moths released in the day may not select the same sites as those that come to rest at the end of their night activity. It seems unlikely that the level of crypsis that would have been achieved by Kettlewell's released moths would have been as great as that of wild moths.

4. The forms of the moth were not released at natural frequencies. If predators, such as birds, had already formed a searching image for the form that was most abundant at a site, this might bias the results (although notably in the opposite direction to the results obtained).

5. The moths that Kettlewell used in his experiments included moth trap-caught wild moths and reared moths. These may have different behaviors, and there exists no record to show whether Kettlewell kept track of the origins of his moths so that he could conduct analysis to look for differences between them. 
6. Some of the moths that Kettlewell used in his Birmingham and Dorset experiments probably did not originate in areas where they were used. This is thought to be the case because typica was scarce at the Birmingham site $(10 \%)$ and carbonaria was absent from the Dorset site at the time (Kettlewell 1973). It is possible that moths develop local adaptations (Howlett and Majerus 1987; Majerus 1998), and so translocated moths (likely to be the typica used in Birmingham and the carbonaria used in Dorset) may have both behaved differently and been under increased stress.

Each of these criticisms, with one exception, was addressed in one or more of the subsequent independent experiments (Cook 2003 for review), prior to Coyne's review in 1998.

The one criticism of Kettlewell's protocol that was not addressed in any of these experiments was that he released moths in the day and so did not allow live moths to select their daytime resting sites at the end of their night flights. This issue has recently been addressed in a predation experiment near Cambridge. The aim of this experiment was to determine whether differences in the levels of bird predation of the typica and carbonaria forms could explain changes in the frequencies of these forms over a period of years.

From 2001 until 2007, the frequencies of the forms of the peppered moth were monitored by trapping at Madingley Wood, to the west of Cambridge. From 2002-2007, a predation experiment was conducted at a site $1.9 \mathrm{~km}$ from Madingley Wood. The experiment was specifically designed to rectify flaws in Kettlewell's predation experiment protocols (Majerus 2005). Thus, the moths used all originated within five $\mathrm{km}$ of the experimental site. Moths were released at low densities and at natural form frequencies for the area. Moths were released onto different parts of trees (103 different release sites) in the ratios that the moths used these parts in the wild. The experiment was conducted each year throughout the moth's flight season. The origin and sex of each moth was recorded prior to release and data for males and females, lab-bred or wild caught, were analyzed separately. Finally, and most crucially, the moths were released into large cages on the trees at dusk (one moth per cage), with the cages being removed in $40 \mathrm{~min}$ before sunrise the following morning. Moths were then observed over a four-hour period and incidences of bird predation recorded (Majerus 2005). After four-hours, any remaining moths were recollected and recorded. The results of this experiment showed that the frequency of carbonaria declined from $12 \%$ of the carbonaria + typica population in 2001 to just over $1 \%$ in 2007. This is equivalent to a mean selection coefficient of 0.29 against carbonaria over this period. In the predation experiment, proportionately more carbonaria were eaten than typica, the difference being equivalent to a selection coefficient of 0.22 against the black form. The difference between these selection coefficients is not statistically significant. The conclusion from this experiment is that differential bird predation of the forms is sufficient to explain the changes in the frequencies of the forms in Cambridge between 2001 and 2007 (Majerus 2007).

\section{Pseudoscientific Criticisms}

Few of those who criticize the peppered moth case as an example of Darwinian evolution in action have ever worked on the moth. Moreover, few have experience as field biologists or training in either evolutionary genetics or ecological entomology. Their criticisms of the case, when erroneous, can thus be excused, at least in part, simply because they have little understanding of the ecology of the moth and its predators, or of how natural selection operates. Yet, although the vacuous nature of some of the criticisms is excusable, they do create a significant problem, because many of the readers of these criticisms, particularly those published in newspapers and on the web, do not have the scientific knowledge or experience to objectively appraise the criticisms.

Take, for example, the first sentence in Chapter 1 of Hooper's Of Moths and Men (Hooper 2002): "To begin at the beginning, the Lepidoptera are divided into two orders: butterflies (Rhopalocera) and moths (Heterocera)." Those who have no experience of entomological classification may not realize that this first sentence is simply wrong. There is a single order of insects called the Lepidoptera (meaning scale wings) to which the butterflies and moths all belong. Within this, those that we call butterflies comprise three superfamilies (Papilionoidea, Hesperioidea, and Hedyloidea) within the order (e.g., Scoble 1992). They are not the most primitive, nor the most advanced in the order. This is a trivial point but illustrates well that, without the necessary background, it is difficult to cogently evaluate the critics of this case. In addition, many of the critics are good writers and are well practiced in arguing their case persuasively.

An example from Hooper (2002), concerning peppered moths and bats, illustrates the problems that nonspecialists have in commenting sensibly on a case such as that of the peppered moth. Prior to publishing Of Moths and Men, Hooper e-mailed me (November 16, 2000) to ask questions about the peppered moth case. One set of questions concerned the role of bat predation and was asked in the context of Hooper's view that Kettlewell thought that $90 \%$ of the predation of adult moths was caused by bats. These questions have previously been published verbatim (Majerus 2005). 
I explained my view in a telephone conversation on November 19, 2000. I cannot remember exactly what I said, but my notes on Hooper's e-mail were that Kettlewell was right that the different forms were unlikely to differ in taste or smell but that scale types and pigments might affect sonar. I also explained why Kettlewell's reasoning was logical and pointed out the flaws in Hooper's argument by theoretical example. Hooper (2002) cites this example (accurately I believe); "Say three hundred eggs are originally laid. Once you get to the adult stage, maybe you have ten left. Of these more than half are killed by things not hunting by sight, so say you have four moths lefttwo typical and two carbonaria. You must be prepared to say that none of the mortality prior to this is due to selection on colour pattern, no pleiotropic effects of alleles, no differences in palatability, no greater energetic costs in producing black pigment and so on. If so, then despite 296 moths being killed up to that point, if those two typicals are eaten by birds, you've increased carbonaria by a hundred per cent at one go."

This simple example was intended to clarify Hooper's obvious misunderstanding of how selection works, as manifest in part of her e-mail, where, in the two questions she asks, she couples and muddles percentage mortalities ( $10 \%$ selectively by birds, $90 \%$ randomly by bats), with the 2:1 and 3:1 selective advantages to one form or the other in Kettlewell's experiments. Yet, my intent was obviously not achieved: I had overestimated Hooper's grasp of how natural selection works. To clarify my clarification, I here spell out my reasoning in more detail.

The female moth that laid 300 eggs was either carbonaria or typica and had mated with a male of the other phenotype. As the difference between carbonaria and typica is due to a pair of alleles of a single gene, with the carbonaria allele being fully genetically dominant to the typica allele (Bowater 1914), the carbonaria moth in this pairing would have to be heterozygous to produce equal numbers of carbonaria and typica offspring. This means that of the 600 alleles present in the 300 eggs laid by this female, three quarters (i.e., 450) would have been typica (two in each of the 150 typica eggs, plus one in each of the 150 carbonaria eggs) and one quarter (i.e., 150) carbonaria (one in each of the 150 carbonaria eggs). By the time we reach the final four moths (two typica and two carbonaria), 444 typica and 148 carbonaria alleles will have been randomly eliminated, leaving just six typica alleles (two in each of the two typica and one in each of the two carbonaria moths) and two carbonaria alleles (one in each of the two carbonaria). If the two typica moths are eliminated before they have reproduced, by birds preying selectively, the remaining two moths that breed and pass on their genes will both be heterozygous for the carbonaria and typica alleles. Thus, now, half the alleles that are passed on are carbonaria. So the final clause in my example: "you've increased carbonaria by a hundred per cent in one go", is realized (from $25 \%$ to $50 \%$ for this family).

Hooper (2002) wrote that Kettlewell's view was that if bat predation did account for $90 \%$ of the predation of adult moths, it did not matter, "because bat predation wasn't differential predation; evolution was driven by the small percentage of moths that are eaten selectively by birds hunting visually". So, although Hooper failed to understand my explanatory example, Kettlewell certainly would have.

Hooper's e-mailed questions, "Wouldn't it be wrong to assume that bat predation was totally random?" and "Would a good scientist need to do an experiment to rule out selective predation by bats?" (Majerus 2005), caused me to design just such an experiment. In four tests in which equal numbers of flying peppered moths of the two forms were made available to bats, bats did not favor either form over the other. In total, bats were seen to eat 211 typica and 208 carbonaria (Majerus 2008). The results support Kettlewell's view that although bats may cause significant mortality in $B$. betularia, they do not prey selectively with respect to $B$. betularia forms.

It is worth noting that although Hooper (2002) asserts that "Kettlewell himself admitted that they \{bats\} probably accounted for 90 per cent of the predation of adult moths.", this was almost certainly not the case. Hooper's reference for this assertion is a letter from Kettlewell to B.J. Lempke, in June 1959. In this letter, Kettlewell wrote: "No one would be foolish enough to argue that your statement 'The greatest enemies of moths are not the birds but the bats' is untrue, but... their predation is not selective. It does not matter the slightest if bats take $90 \%$ of a species population at random on the wing but if birds...account for the other $10 \%$, but do so selectively...". Hooper interprets these figures of $90 \%$ bat predation and $10 \%$ bird predation - used as explanatory example to illustrate a specific point - to be what Kettlewell believed the actual levels of predation by bats and birds were. Yet, it is clear from Kettlewell's writings on the peppered moth that he had a very thorough knowledge of the behavior of this species and did not believe that bats, which feed mainly on flying insects, were responsible for $90 \%$ of the predation of B. betularia adults. This is, for example, manifest when he notes that, in a resting site selection experiment, he and Conn used only females, "which do not normally fly" (Kettlewell 1973, p. 88, footnote). Here, Kettlewell preempts the findings of Liebert and Brakefield, who demonstrated that female $B$. betularia rarely fly, except for a single dispersal flight following mating, usually on the second night after eclosion (Liebert and Brakefield 1987). That Hooper gets so much wrong in this small facet of the peppered moth story may be a function of the agenda that she was writing to, or, more probably, was a result of Hooper understanding neither how 
natural selection operates nor how peppered moths behave and interact with their predators.

My own view, based on both literature and field observation, is that while bat predation of day-cryptic night-flying moths in the summer is considerable, it will differ in level between the sexes of a species because of the variation in the amount that the sexes fly. In the peppered moth, I doubt that bat predation accounts for as much as $90 \%$ of total predation on adult males, and I am certain that it accounts for only a small proportion of the total predation of females.

\section{Data Manipulation and/or Scientific Fraud}

Finally, we come to suggestions that Kettlewell designed his experiments, "in order to come up with the right answer" (Matthews 1999), or changed his experimental protocols or data in a deceptive manner (Hooper 2002). Rudge (2005) considers Hooper's accusation of scientific fraud in considerable detail. While not wishing to repeat his deft, surgical dissection of Hooper's flawed agenda ("She decided in advance that she wanted to tell an entomological whodunnit."), three major points in Rudge's arguments are worth detailing. First, he notes that, "among the many scientists who have worked on the phenomenon over the last 50 years, neither Kettlewell's colleagues, nor his severest critics, nor researchers since have ever alleged that he committed fraud: nor has any historian of biology."

Second, he points out that one of Hooper's strongest accusations was that Kettlewell changed his release procedure (increasing the number of moths released) to try to increase the numbers of marked moths that were recaptured and ties this to her own unsubstantiated interpretation of a letter that Ford wrote to Kettlewell on July 1, 1953. She wrote, referring to Kettlewell's 1955 paper, "there is a table, Table 5, listing releases, catches and recaptures for each day. Squinting at the columns of numbers, we notice a strange thing: from 1 July on, after the letter from his boss, the recaptures suddenly soar." Both Rudge (2005) and Majerus (2005) note that the timings of the changes in procedure do not fit with this interpretation. Kettlewell changed his protocol on June 30, presumably in response to the low recapture rates that he had informed Ford of. Moreover, the increase in recapture rates was first recorded on July 1 and would represent the moths found in his traps early in the morning following the night of June 30/July 1, i.e., before Ford had written his letter. Third, from his comprehensive review of Hooper's accusation that Kettlewell committed fraud, in which he examined her book, the sources that she cites and many other sources of the peppered moth that Hooper fails to cite, Rudge (2005) concludes, "that Hooper (2002) does not provide one shred of evidence to support this serious allegation."
In conclusion, to answer the question of whether the criticisms of the peppered moth story are justified, each of the classes of criticism should be considered separately. Certainly, the criticisms in the first two classes, pertaining to lack of knowledge of some aspects of the behavior and ecology of the moth and to the artificiality in some of the experiments, were justified. Indeed, many of these criticisms have been accepted by the scientists they were aimed at and in some cases the criticisms were selfcriticisms. Moreover, most of these weaknesses in the case have been addressed and answered over the last half century.

The pseudoscientific criticisms are themselves so flawed as a result of lack of either objectivity or understanding, or both, that they are clearly unjustified and, as such, need no further response. Finally, the accusations of fraud have been found to be vacuous, unsubstantiated, and unsustainable. While scientifically they require no further consideration, as they denigrate the reputations of two dead scientists, it is to be hoped that those who invented them and others who have repeated them will retract and apologize for these accusations in print.

\section{Should the Peppered Moth Story be Taught as an Example of Darwinian Evolution in Action?}

Whether Coyne (1998), in his review of Melanism: Evolution in Action (Majerus 1998), was correct in considering the case of the peppered moth, "to be in bad shape," is open to question. What is certain is that work over the decade since Coyne wrote these words has placed the peppered moth story back on solid ground, with its reputation as the prime example of Darwinian evolution restored. The work over the last decade has provided evidence of where wild peppered moths spend the day and has shown that bats cannot account for observed changes in the form frequencies and that differential bird predation can. However, this new evidence changes the story of industrial melanism in the peppered moth that has been taught in schools and colleges over the last half century very little. Majerus (1998) wrote, in the conclusion to his analysis of the peppered moth story, that "My view of the rise and fall of the melanic peppered moth is that differential bird predation in more or less polluted regions, together with migration, are primarily responsible, almost to the exclusion of other factors." That is still my view.

Antievolution lobbyists, who expressed concerns over the artificiality and other weaknesses in Kettlewell's experimental methods, should receive the new evidence that has been accumulated over the last decade warmly. Their concerns have been answered. More importantly, teachers in schools and colleges, who have been worried 
that they may have been teaching an example based on flawed science, can now return to teaching the story of industrial melanism in the peppered moth with confidence. Here is a story that is easy to understand, makes logical sense, and can be easily explained to a class of students. Moreover, the hypothesis on which the story is based has been used to make predictions that have been tested and verified, while other potential explanations have been refuted (e.g., Kettlewell 1973; Majerus 1998; Ford 1964). Thus, the peppered moth case can not only be used as a superb example of Darwinian evolution in action but also to illustrate how good science is done (Rudge 2004). Within the case, again and again, the methodology of "good science:" observation-hypothesis formation-prediction formulationexperimental testing-and verification or refutation of the hypothesis, can be seen. The researches on Tutt's hypothesis to explain the observations of increasing carbonaria frequencies in the nineteenth century and Kettlewell's experimental tests which confirmed this hypothesis, the many studies showing that the predicted decline in carbonaria following antipollution legislation has and is being realized, or my own simple experiment leading to the refutation of the hypothesis that bats predate the forms differentially, all follow good science practice.

Most objective scientists who have examined the story in detail in the last half century have never veered from the view that the rise of carbonaria in polluted habitats was largely a consequence of differential bird predation. So, one has to wonder why this particular example has been so heavily targeted by antievolutionists. Certainly, there are many other examples in which natural selection has been observed, from antibiotic resistance in bacteria to pesticide resistance in mammals and numerous insects, to heavy metal tolerance in many plants, to changes in beak shape in Galapagos finches, to the origin of new species by polyploidy, and on and on. So why has the peppered moth been singled out? I think that the reason is simply that the peppered moth story is the most accessible teaching example of Darwinian evolution through the process of natural selection.

Douglas Adams (2002), in an essay in The Salmon of Doubt, wrote, "even today that persists as a slightly tricky problem if you are trying to persuade somebody who doesn't believe in this evolution stuff and wants you to show him an example - they are hard to find in terms of everyday observation." But the peppered moth story is easy because it does involve elements that most people are familiar with: birds and moths, color and vision, camouflage and pollution, and dinner and death. The antievolution lobby is worried that if the peppered moth story is allowed to stand, too many people will be able to understand.

One major positive outcome has resulted from the subjective criticisms aimed at the peppered moth story between 1998 and 2003. It is that these criticisms catalyzed both academic comment on the criticisms (e.g., Cook 2003; Mallett 2004; Rudge 2003, 2005; Grant 2002), reanalysis of data (Young and Musgrave 2005), and empirical research to address the criticisms (e.g., Majerus 2005, 2007, 2008). The targeting of the peppered moth story may now backfire on the antievolutionists. Unless those that Kohn (2004) has termed, "the moth-bothering Darwin-baiters" now concede the validity of the case as an example of Darwinian evolution in action, they will reveal themselves as biased, subjective, and unscientific.

\section{Postscript}

Many of the anti-Darwinian critics of the peppered moth case argue that alternatives, such as Special Creation and Intelligent Design, should be taught in biology class as an alternative to Darwinian selection theory as an explanation of adaptive evolution. However, unlike Darwinian selection theory, which makes predictions that have been tested and verified, creationist alternatives make no predictions and cannot be tested. They are not science. Consequently, they should not be taught in biological science class.

Of course, such creationist ideas may and indeed should be taught elsewhere in schools and colleges, such as in philosophy, history, or religious studies classes. Here, issues relating to faith and fact are correctly discussed and judged. It is to be hoped that the idea of Intelligent Design will in future be carefully considered in such classes against the classical example of Tutt's differential bird predation hypothesis to explain the rise of the black peppered moth in industrial Victorian England. An analysis of the different approaches of journalists, who want a "good story," of the antievolution lobbyists who have commented on the case and of the experimental scientists who have worked on the case would be an excellent and illuminating illustrative case study to allow students to critically appraise the methodologies and philosophies of the three groups. Consequently, the peppered moth may become not only one of the best teaching examples of Darwinian evolution in action that we have but also a bedrock example of the difference between science and nonscience.

\section{References}

Adams D. The salmon of doubt. London: Macmillan; 2002.

Bishop JA. An experimental study of the cline of industrial melanism in Biston betularia (L.) (Lepidoptera) between urban Liverpool and rural North Wales. J Anim Ecol. 1972;41:209-43. doi:10.2307/3513.

Bishop JA, Cook LM, Muggleton J. The response of two species of moths to industrialization in northwest England. I. Polymorphism 
for melanism. Philos Trans R Soc Lond B Biol Sci. 1978a;281:489-515. doi:10.1098/rstb.1978.0006.

Bishop JA, Cook LM, Muggleton J. The response of two species of moths to industrialization in northwest England. II. Relative fitness of morphs and population size. Philos Trans R Soc Lond B Biol Sci. 1978b;281:517-42. doi:10.1098/rstb.1978.0007.

Bowater W. Heredity of melanism in Lepidoptera. J Genet. 1914;3:299-315.

Brakefield PM. Industrial melanism: do we have the answers? Trends Ecol Evol. 1987;2:117-22. doi:10.1016/0169-5347(87)90051-6.

Brakefield PM. A decline of melanism in the peppered moth, Biston betularia in The Netherlands. Biol J Linn Soc Lond. 1990;39:327-34. doi:10.1111/j.1095-8312.1990.tb00520.x.

Brakefield PM, Liebert TG. The reliability of estimates of migration in the peppered moth Biston betularia and some implications for selection-migration models. Biol J Linn Soc Lond. 1990;39:33542. doi:10.1111/j.1095-8312.1990.tb00521.x.

Brakefield PM, Liebert TG. Evolutionary dynamics of declining melanism in the peppered moth in The Netherlands. Proc R Soc Lond B Biol Sci. 2000;267:1953-7. doi:10.1098/rspb.2000.1235.

Clarke CA, Sheppard PM. Genetic control of the melanic form insularia of the moth Biston betularia L. Nature. 1964;202:2156. doi:10.1038/202215a0.

Clarke CA, Mani GS, Wynne G. Evolution in reverse: clean air and the peppered moth. Biol J Linn Soc Lond. 1985;26:189-99. doi:10.1111/j.1095-8312.1985.tb01555.x.

Cook LM. Changing views on melanic moths. J Linn Soc. 2000;69:431-41. doi:10.1111/j.1095-8312.2000.tb01215.x.

Cook LM. The rise and fall of the carbonaria form of the peppered moth. Q Rev Biol. 2003;78:399-417. doi:10.1086/378925.

Cook LM, Askew RR, Bishop JA. Increasing frequency of the typical form of the peppered moth in Manchester. Nature. 1970;227:1155. doi:10.1038/2271155a0.

Coyne JA. Not black and white. Nature. 1998;396:35-6. doi:10.1038/ 23856.

Edleston RS. No title (first carbonaria melanic of moth Biston betularia). Entomologist. 1864;2:150.

Ford EB. Ecological genetics. London: Methuen; 1964.

Frack D. Peppered moths - in black and white. Posting to 'Anticreation List', anticreation@talkorigins.org, March 30, 1999.

Grant BS. Sour grapes of wrath. Science. 2002;297:940-1. doi:10.1126/science.1073593.

Grant BS, Owen DF, Clarke CA. Decline of melanic moths. Nature. 1995;373:565. doi:10.1038/373565a0.

Grant BS, Owen DF, Clarke CA. Parallel rise and fall of melanic peppered moths in America and Britain. J Hered. 1996;87:351-7.

Hooper J. Of moths and men: intrigue, tragedy \& the peppered moth. London: Fourth Estate; 2002.

Howlett RJ, Majerus MEN. The understanding of industrial melanism in the peppered moth (Biston betularia) (Lepidoptera: Geometridae). Biol J Linn Soc Lond. 1987;30:31-44. doi:10.1111/ j.1095-8312.1987.tb00286.x.

Kettlewell HBD. Selection experiments on industrial melanism in the Lepidoptera. Heredity. 1955;9:323-42. doi:10.1038/hdy.1955.36.

Kettlewell HBD. Further selection experiments on industrial melanism in the Lepidoptera. Heredity. 1956;10:287-301. doi:10.1038/ hdy.1956.28.

Kettlewell HBD. A survey of the frequencies of Biston betularia (L.) (Lepidoptera) and its melanic forms in Great Britain. Heredity. 1958a;12:51-72. doi:10.1038/hdy.1958.4.

Kettlewell HBD. The importance of the micro-environment to evolutionary trends in the Lepidoptera. Entomologist. 1958b;91:214-24

Kettlewell HBD. The evolution of melanism. Oxford: Clarendon; 1973.

Kohn M. A reason for everything: natural selection and the English imagination. London: Faber and Faber; 2004.
Lees DR. Genetic control of the melanic form insularia of the peppered moth Biston betularia L. Nature. 1968;220:1249-50. doi:10.1038/2201249a0.

Lees DR. Industrial melanism: genetic adaptation of animals to air pollution. In: Bishop JA, Cook LM, editors. Genetic consequences of man made change. London: Academic; 1981. p. 129-76.

Lees DR, Creed ER. Industrial melanism in Biston betularia: the role of selective predation. J Anim Ecol. 1975;44:67-83. doi:10.2307/ 3852.

Liebert TG, Brakefield PM. Behavioural studies on the peppered moth Biston betularia and a discussion of the role of pollution and epiphytes in industrial melanism. Biol J Linn Soc Lond. 1987;31:129-50. doi:10.1111/j.1095-8312.1987.tb01985.x.

MacArthur RH, Connell JH. The biology of populations. New York and London: Wiley; 1966.

Majerus MEN. Melanism: evolution in action. Oxford: Oxford University Press; 1998.

Majerus MEN. The peppered moth: decline of a Darwinian disciple. In: Fellowes MDE, Holloway GJ, Rolff J, editors. Insect evolutionary ecology. Wallingford, UK: CABI; 2005. p. 367-91.

Majerus MEN. The peppered moth: the proof of Darwinian evolution. Available at http://www.gen.cam.ac.uk/Research/Majerus/Sweden talk220807.pdf, 2007.

Majerus MEN. Non-morph specific predation of peppered moths (Biston betularia) by bats. Ecol Entomol. http://www3.interscience.wiley. com/journal/120122275/abstract?CRETRY=1\&SRETRY=0, 2008.

Mallett J. The peppered moth: a black and white story after all. Genet Soc News. 2004;50:34-8.

Mani GS, Majerus MEN. Peppered moth revisited: analysis of recent decreases in melanic frequency and predictions for the future. Biol J Linn Soc Lond. 1993;48:157-65. doi:10.1111/j.10958312.1993.tb00884.x.

Matthews R. Scientists pick holes in Darwin moth theory. The Sunday Telegraph, March 14, 1999.

Mikkola K. Resting site selection of Oliga and Biston moths (Lepidoptera: Noctuidae and Geometridae). Acta Entomol Fenn. 1979;45:81-7.

Mikkola K. On the selective force acting in the industrial melanism of Biston and Oliga moths (Lepidoptera: Geometridae and Noctuidae). Biol J Linn Soc Lond. 1984;21:409-21. doi:10.1111/ j.1095-8312.1984.tb01602.x.

Raeburn P. The moth that failed. The New York Times, July 25 section 7, p. 3, 2002.

Rudd S. The piltdown moth. http://www.bible.ca/tracks/textbookfraud-pepper-moth-biston-betularia.htm, 2001.

Rudge DW. The role of photographs and films in Kettlewell's popularizations of the phenomenon of industrial melanism. Sci Educ. 2003;12:261-87. doi:10.1023/A:1024031432066.

Rudge DW. Using the history of research on industrial melanism to help students better appreciate the nature of science. In Proceedings of the Seventh International Teaching Group Meeting Winnipeg 761-772 (available through http://ihpst.arts.unsw.edu. au/index.html), 2004.

Rudge DW. Did Kettlewell commit fraud? Re-examining the evidence. Public Underst Sci. 2005;14:249-68. doi:10.1177/ 0963662505052890.

Scoble MJ. The Lepidoptera: form, function and diversity. London: British Museum (Natural History); 1992.

Smith PD. Darwinism in a flutter: did a moth show evolution in action? The Guardian, May 11, 2002.

Steward RC. Industrial and non-industrial melanism in the peppered moth Biston betularia (L.). Ecol Entomol. 1977;2:231-43. doi:10.1111/j.1365-2311.1977.tb00886.x.

Tutt JW. British moths. London George: Routledge; 1896. 
Wade N. Staple of evolutionary history may not be a textbook case. The New York Times, June 18 section F, p. 3, 2002.

Wells J. Second thoughts about peppered moths: this classical story of evolution by natural selection needs revising. The True Origin Archive, http://trueorigin.org/pepmoth1.htm, 2001.

Wells J. Moth-eaten statistics: a reply to Kenneth R. Miller. Discovery Institute: Centre for Renewal of Science and Culture-Article Database, http://www.discovery.org/viewDB/index.php3?com mand=view\&id=1147\&program=CRSC, 2002.
Whittle PDJ, Clarke CA, Sheppard PM, Bishop JA. Further studies on the industrial melanic moth Biston betularia (L.) in the northwest of the British Isles. Proc R Soc Lond B Biol Sci. 1976;194:46780.

Yoon CK. Parallel plots in classic of evolution. New York Times: Science Times, November 12, pp C1, C7; 1996.

Young M, Musgrave I. Moonshine: why the peppered moth remains an icon of evolution. Skeptical Inquirer March-April 23-28, 2005 . 